\title{
Lorenzo Chiesa, The Not-Two: Logic and God in Lacan
}

\author{
Cambridge, MA: MIT Press, 2016, 251 pp., ISBN 9780262529037
}

\author{
Reviewed by Valeria Levchuk \\ European University at St Petersburg
}

Lorenzo Chiesa's The Not-Two: Logic and God in Lacan is centered around a profound endeavor to unpack Jacques Lacan's crucial theoretical axiom "there is no sexual relationship" with regard to its ontological, anthropological, and practical consequences. Following Lacan, Chiesa claims that the core of our linguistic subjectivity is based on the impossibility of a symmetrical ratio between sexes. The non-existence of sexual relationships nevertheless engenders sexed liaisons, which are sustained by the transcendental logic of the phallic function, aimed at simultaneously veiling and suturing this irreducible impossibility. The entirety of our linguistic representations and the imaginary domain it gives rise to depends on the logical impasse, that is, the impossibility of equally inscribing the two sexes into the symbolic. The "not-two" of the sexes, where man is sexed as caught into the semblance of the One, and woman only partially exists in the logic of sexuation, opens up a vertiginous perspective of tracing the emergence and constitution of any potential symbolic-imaginary structure resulting from it. In order to do so, Chiesa turns to the so-called "God hypothesis" from late Lacan. The "God hypothesis," he argues, is the way the initial deadlock phenomenally presents itself within any linguistic structure.

Along these lines, Chiesa poses three cardinal questions that outline the field of this book's research. The first of these is attentively and closely approached throughout the book, whereas the other two are to be addressed in later investigations:

(1) The first question concerns the basic principles of phallic function and the transcendental logic of sexuation that departs from the field of traditional logic. Lacan uses the phallic function to translate the Freudian Oedipus complex into logical terms. For Lacan it is precisely the way in which the phallic function engenders the semblance of the One that compensates for the logical impasse of the non-existence of the sexual 
relationship and becomes a core of linguistic sexuation/subjectivation. (2) The second interrogation points out the nature of the One. Can we ever have an authentic experience of the One, or is it merely a structural effect concealing the deadlock that founds it?

(3) And finally, the non-existence of the sexual relationship-formulated in ontological terms as the truth of incompleteness-introduces a difficulty that any philosophical theoretical initiative, cognizant of the Lacanian psychoanalytic enterprise, inevitably has to deal with: How is the truth of incompleteness to be stated without it becoming another "truth about truth" and therefore collapsing back into the domain of imaginary wholeness?

In spite of Lacan's well-known reluctance to found another ontology-an ontology that could potentially be based upon his interrogations into the incompleteness of language and meditations on the instance of the One-Chiesa nevertheless suggests that it is possible to carefully elaborate the new perspectives opened up by Lacan's thinking in ontological terms. Moreover, Chiesa's research in the present book situates itself in interdisciplinary territory. Such a cross-disciplinary position is required in order to fully acknowledge the questions raised by a close reading of Lacan for, above all, philosophical thought. In this regard, the book opens up a broad horizon of ontological, anthropological, and logical-theoretical developments in dialogue with contemporary debates within logic, physics, biology, and neuroscience. Chiesa's book also stands alongside other significant theoretical initiatives, working upon the elaboration of new ontologies from the standpoint of a "psychoanalytically informed philosophy” (Adrian Johnston, Slavoj Žižek) (Chiesa 2016: XVIII).

In chapter 1 , Chiesa explores the connection between sexual difference and the "God hypothesis" as developed by Lacan in Seminar XX. The process of sexuation/subjectivation that results from the absence of the sexual relationship is an overcomplicated means by which speaking beings compensate for the fact that there is no singular way of arriving at a symmetrical and transparent relation between the sexes within the domain of language. This process generates two positions for speaking beings to assume and, in this way, to some extent to overcome the underlying logical impasse: that of man and that of woman. Both sexes don't directly relate to each other, their relation is mediated only through the function of the phallus. In this way, the phallic function is a transcendental function that allows for sexed liaisons and ensures that reproduction somehow takes place thanks to the figure of the One. Men and women situate themselves differently in relation to the One, an imaginary semblance of totality that appears in the place of a non-existent fusion. A subject sexed as man oscillates between the desire for the One and the impossibility of its totalization, whereas a subject sexed as woman is not 
wholly submitted to the phallic function, occupying a paradoxical position outside of the symbolic (not-One). So the question is how exactly men and women come to terms with the fundamental inconsistency of the symbolic, which initially originates in the impossibility of a reciprocal and complementary symbolization of the sexes.

Of particular interest in this chapter is Chiesa's polemic against a common erroneous reading of Seminar XX, which understands woman as the Other sex. According to Chiesa, it is precisely the structural loop of male sexuation: men strive to totalize women as the other sex (in the guise of the One), but always fail to do so, because a woman is not fully caught into the phallic function. The initial impossibility of representing woman as One, that is, the missing of the other sex, evokes the figure of God, which is nothing but a name for the inconsistency of the symbolic order-the oscillation between the strive for totalization, making One from the other (missing) sex, and the ongoing failure to do so.

Chapter 2 is mostly devoted to a compelling engagement with the life sciences and postulates the potential biological implications of Lacanian psychoanalysis. In this chapter, Chiesa moves beyond Lacan and discusses the very nature of the deadlock that the logic of sexuation/subjectivation is founded upon. The highly complex issue at stake here is the question of whether sex and sexual difference in psychoanalysis are to be understood as exclusively linguistic structures that wholly negate any biological conditioning, or remain in some way connected to biological matter, and if so, how this matter is to be positively grasped within the domain of language. Following Lacan, Chiesa argues that sexual difference as such is not something that is directly given to speaking beings, but is rather formed retroactively. Unlike the life sciences that present sex as a natural fact and, moreover, in which the two sexes are often thought to be initially complementary to one other, Lacanian psychoanalysis manifests the indifference of the anatomical "little difference" between sexes as a logical deadlock for a child, which only retroactively emerges as the "two" of sexual difference (i.e., the two sexes). Yet this latter also necessarily leads to an impasse because of the symbolic underdetermination of the second sex.

According to Lacan, all notions of the natural sciences remain situated within an imaginary domain that evokes a phantasy of copulation in the guise of a harmonious fusion of two complementary parts. Moreover, nature is presented as something that has always been there and has always existed in such a fashion, independent of human cognition. Lacan's argument complicates this in its twofold structure; for Lacan, discourse is without consequence for nature, which means that the latter is fundamentally indifferent in itself to the symbolic. Yet, at the same time, there is such thing as "discursive nature," that is, the retroactively formed symbolic and imaginary representation of the initial anatomical given, which is imaginarily grasped as the two of the sexes always-already there. 
Following Lacan, Chiesa poses a crucial question regarding this issue: How is nature-in itself indifferent to any signification and to the symbolic as such-to be nonetheless conceived of as something that generates the symbolic and, therefore, sexual difference? In this chapter, Chiesa convincingly sustains a polemic with Slavoj Žižek and Adrian Johnston, both of whom similarly examine the emergence of the symbolic within the framework of their ontological projects, following upon and further developing the implications of Lacan's thought. Departing from their shared critique of Quentin Meillassoux and his highly problematic idea of science as able to produce facts about a reality which would precede the symbolic order, each suggests a different way of positively grasping a pre-symbolic that supposedly engenders the domain of difference. According to Chiesa, Žižek ends up proposing a kind of negative vitalism of the real with his notion of constitutive negativity, whereas Johnston effects a projection of symbolic inconsistency onto "nature as such," using Hegel's notion of "weak nature" for his own conceptualisation of nature as inconsistent-in-itself. The main problem for Chiesa is that Žižek, as well as Johnston, fail to think of the pre-symbolic as fundamentally indifferent to the symbolic and hence absolutely contingent. Therefore, Chiesa proposes thinking about the pre-symbolic of the anatomical "little difference" as, foremost, profoundly indifferent to sexual difference as we understand it from the standpoint of the symbolic.

This thesis requires a clarification of the "God hypothesis," that is, an understanding of it as something that presents the structural inconsistency of the symbolic on a phenomeno-logical level as an impasse between One and not-One. For Chiesa, it's a matter of not-deciding between the truth of incompleteness (One) and the contingency and inconsistency of the "natural" preconditions that form the symbolic and that we will never be able to fully comprehend (not-One or the barred real in Lacanese); between God as One, which is the inevitable semblance any structure gives rise to, and between the evil, deceitful God of Descartes who is the divine embodiment of the barred real itself. Chiesa proposes a position in between a critical awareness of the incompleteness of any linguistic structure, (one that can only be half-said), and the inconsistency itself. Within his para-ontological project it is precisely this gap that can open up a domain of freedom for the speaking subject. Finally, Chiesa suggests fulfilling the truth of incompleteness within a practical and political dimension as our "true truth," rather than stating it as an ontological position, which immediately engenders a metalinguistic statement leading to an illocutionary suicide; and acting as if the deceitful God, the foundational inconsistency of the symbolic, were not there.

In chapter 3, Chiesa introduces the complex relationship between Lacanian psychoanalysis and logic. He argues that Lacan develops a logic of sexuation as a means to formalize the barred real, that is, the very impossibility of symbolizing sex that founds the order of language. The 
structural incompleteness of the symbolic introduces a dialectics of truth and semblance, which is precisely what the phallic function represents. Contrary to most other discourses that treat truth as something that is hidden or distorted by semblance, Lacanian psychoanalysis, according to Chiesa, rather unveils and (using logic) formalizes the connection between truth and semblance as that of a dialectics.

In chapter 4, Chiesa carefully unpacks the formulas of sexuation from Seminar XX. The main point of this attentive investigation is to show exactly how it is that sexed liaisons function, notwithstanding the logical deadlock of the contingent biological premise they are founded upon.

In the concluding part of the book, Chiesa explores the primacy of number as the ultimate truth of structure over and above the logical inscription of the formulas of sexuation. If the final truth of structure is the oscillation between One and not-One, between the absolute truth of incompleteness and the barred real itself, the solution lies for Chiesa in a practical and political domain. Here Chiesa repeats his thesis: for paraontology, it is, firstly, a matter of truly not-deciding between the two alternatives, because each apparently entails a highly problematic ontological position (whether it be the assertion of an ultimate truth of incompleteness or a presupposition of a structural inconsistency in the form of a malicious divine essence). As an answer to this dilemma, Chiesa suggests practically and ethically performing the truth of incompleteness as our "true truth," all the while-at an ontological level-remaining consciously undecided between the two described alternatives.

Chiesa's book occupies a seminal position among contemporary philosophical developments of Lacanian theory. A rigorous theoretical work, it not only provides us with one of the most careful and attentive examinations of the logics of sexuation in Lacan, but, just as importantly, shows how such an attentive reading of sex and sexual difference can shed light on the core philosophical and practical questions that arise from Lacanian psychoanalytic theory: the question of the limits of language, the question of formalization, the question of the connection between psychoanalysis and science, and so forth. Moreover, although The Not-Two presents a highly sophisticated philosophical work that seeks to elaborate ontological questions beyond Lacan, the book succeeds in providing a cogent and invaluable insight into the basic axioms of Lacanian theory, dealing with the connection between sex and language. Chiesa's take on the the dialectics of truth and semblance is of profound value when it comes to establishing the theoretical identity of Lacanian psychoanalysis, especially regarding its highly problematic position within the university. Finally, his theoretical endeavor outlines a fascinating and rich perspective for elaborating the practical and political dimension of psychoanalysis within the framework of a philosophical project for years to come. 